\title{
PENYULUHAN KESEHATAN PENCEGAHAN PENYAKIT TUBERKULOSIS DAN PENGOBATAN GRATIS DI PESANTREN SABILUNNAJAT
}

\section{HEALTH PROMOTION PREVENTING OF TUBERCULOSIS DISEASE AND FREE MEDICAL TREATMENT AT SABILUNNAJAT BOARDING $S C H O O L$}

\author{
${ }^{1)}$ Nazarwin Saputra*, 1) Abul A'la Al Maududi, ${ }^{1)}$ Nur Armilah Sadiah \\ ${ }^{1)}$ Program Studi Kesehatan Masyarakat, Fakultas Kesehatan Masyarakat \\ Universitas Muhammadiyah Jakarta \\ Alamat: Jl. K.H. Ahmad Dahlan, Cireundeu, Ciputat, Tangerang Selatan \\ "Email: nazarwinepid@gmail.com
}

\begin{abstract}
ABSTRAK
Kasus tuberkulosis masih menjadi masalah kesehatan yang serius baik global maupun lokal. Penanggulangan tuberkulosis telah diatur dalam peraturan menteri kesehatan nomor 67 tahun 2016 diantaranya pengendalian risiko salah satunya promosi kesehatan untuk pencegahan. Pesantren sabilunnajat ciamis belum pernah dilakukan program penyuluhan kesehatan dan sebagai dukungan program kementerian kesehatan maka dilakukan pengabdian masyarakat dalam bentuk penyuluhan kesehatan untuk pencegahan tuberkulosis. Metode pengabdian masyarakat dilakukan dengan metode ceramah dilanjutkan sesi tanya jawab dengan sasaran para santri di Pondok Pesantren Sabilunnajat Ciamis. Pengabdian masyarakat ini diselenggarakan pada tanggal 21 hingga 23 Februari 2020. Sebelum dan sesudah penyuluhan santri diberikan pre test dan post test. Hasilnya menunjukkan bahwa terdapat perbedaan tingkat pengetahuan antara sebelum dan sesudah penyuluhan kesehatan pencegahan penyakit tuberkulosis di Pondok Pesantren Sabilunnajat. Kegiatan lainnya yang dilakukan yaitu pengobatan gratis untuk santri. Disarankan kepada pihak sabilunnajat agar selalu menjaga kesehatan dan menerapkan perilaku hidup bersih dan sehat kepada para santri.
\end{abstract}

Kata kunci : penyuluhan, pencegahan, tuberculosis

\begin{abstract}
Tuberculosis is still a serious health problem both globally and locally. Tuberculosis prevention has been regulated in the Minister of Health Regulation number 67 of 2016 including risk control, one of which is health promotion for prevention. The pesantren sabilunnajat ciamis has never done a health education program and as a support of the ministry of health program, community service is carried out in the form of health education for tuberculosis prevention. The method of community service is carried out by the lecture method followed by a question and answer session targeting the students at the Sabilunnajat Ciamis Islamic Boarding School. This community service was held from 21 to 23 February 2020. Before and after counseling students were given pre-test and post-test. The results show that there are differences in the level of knowledge between before and after health education on tuberculosis prevention at Sabilunnajat Islamic Boarding School. Other activities undertaken are free medical treatment for students. It is recommended to the sabilunnajat to always maintain health and apply clean and healthy living behaviors to the students.
\end{abstract}

Keyword: counseling, prevention, tuberculosis 


\section{PENDAHULUAN}

Kasus tuberkulosis (TBC) masih menjadi masalah kesehatan yang serius. Kematian karena tuberkulosis mencapai diperkirakan 1,3 juta pasien dan ditemukan kasus baru sebanyak 6,4 juta Kasus tuberculosis secara global. Kasus baru TBC sebanyak 319 per 100.000 penduduk dengan angka kematian 40 per 100.000 penduduk tahun 2017 di Indonesia. Case detection rate di Provinsi Jawa Barat mencapai $71 \%$ tahun 2018. (WHO, Global Tuberculosis Report, 2018, Kemenkes RI, 2019).

Tuberkulosis adalah penyakit infeksius menular melalui droplet yang disebabkan oleh Mycobacterium tuberculosis (WHO, 2014). Sumber penularan penyakit ini adalah pasien TBC terutama pasien yang mengandung kuman TBC dalam dahaknya. Pemerintah sendiri telah mengatur penanggulangan TBC dengan adanya PMK 67 tahun 2016 yang tujuannya adalah melindungi masyarakat dari penulatan TBC agar tidak terjadi kesakitan, kematian dan kecacatan dengan target diharapkan dampak pada tahun 2020 penurunan angka kesakitan karena TBC sebesar 30 persen dibandingkan angka 2014 dan penurunan angka kemarian karena TBC sebesar 40 persen dibandingkan tahun 2014. Salah satu strategi penanggulangan TBC dalam pencapaian eliminasi TBC nasional adalah pengendalian faktor risiko dengan diantaranya peromosi lingkungan dan hidup sehat, penerapan pencegahan dan pengendalian infeksi TBC (menteri kesehatan RI, 2016).

Ada hubungan antara tingkat pengetahuan dengan kejadian tuberculosis. Begitu juga dengan tindakan/praktik juga berhubungan signifikan dengan kejadian tuberkulosis. Maka dari itu penting dilakukan penyuluhan kesehatan pencegahan TB di masyarakat. ( Setiarni SM, Sutomo AH, Hariyono W, 2011, Wenas, AR, Kandou GD, Rombot DV, 2015) Hasil survey awal yang sudah pernah kami lakukan sebelumnya menyatakan bahwa memang belum pernah dilakukan penyuluhan kesehatan di pesantren untuk pencegahan tuberkulosis. Maka kami melakukan pengabdian masyarakat di pesantren tersebut dalam bentuk penyuluhan kesehatan pencegahan TBC dengan sasaran para santri, selain itu kami juga melakukan pengobatan gratis untuk santri.

\section{METODE}

Pengabdian masyarakat ini dilakukan dalam bentuk penyuluhan masal pada santriawan dan santriwati di lingkungan pesantren sabilunnajat. Kegiatan ini dilakukaan pada tanggal 21 hingga 23 Februari 2020, alat bantu pengabdian masyarakat diantaranya alat pengeras suara, slide power point mater serta LCD proyektor. Mitra pengabdian masyarakat ini adalah pihak pengurus Pondok Pesantren Sabilunnajat Ciamis. Sebelum dilakukan penyuluhan kesehatan untuk mencairkan suasana kami melakukan penyegaran suasana dengan games ringan. Dalam pengabdian masyarakat ini kami melibatkan juga mahasiswa S1 Kesehatan Masyarakat Universitas Muhammadiyah Jakarta. Perannya sebagai asistensi lapangan. Setelah penyegaran suasana kami membagikan kuesioner pre test untuk mengukur sejauh mana pengetahuan pada santri terkait pencegahan TBC. Setelah pre test selesai dilanjutkan dengan materi pencegahan tuberkulosis. Sesi selanjutnya adalah Tanya jawab. Lalu dilanjutkan dengan post test. Setelah semua selesai. Hasil pre test dan post test dilakukan analysis untuk mengukur keberhasilan pengabdian masyarakat apakah ada perbedaan setelah dilakukan penyuluhan kesehatan.

\section{HASIL DAN PEMBAHASAN}

Pesantren Sabilunnajat terletak di Rancah, Dusun Sukamaju, Desa Cileungsir, Kabupaten Ciamis, Jawa Barat. Pesantren ini berdiri tahun 1965 oleh Kyai Hasan Ma'ruf dan tercatat sebagai lembaga pendidikan yang sah tahuan 1993. 
Pengabdian masyarakat ini dilaksanakan sebagai upaya pemerintah dalam mengendalikan risiko penyakit tuberculosis dan menyemarakkan catur dharma perguruan tinggi Universitas Muhammadiyah Jakarta. Dari hasil pengabdian masyarakat yang telah dilakukan didapatkan hasil bahwa terdapat perbedaan antara sebelum dan sesudah penyuluhan kesehatan (p:0,001). Peningkatan pengetahuan pada santri tersebut diharapkan dapat diiringi dengan praktik pencegahan dikeseharian dan aktivitas sehari hari di pesantren. Tingkat keingintahuan para santri cukup baik dibuktikan dengan keaktifan ketika sesi Tanya jawab. Setelah kegiatan penyuluhan kesehatan ini maka diagendakan kegiatan selanjutnya diantaranya pembentukan kader sehat dan poskestren di Pesantren Sabilunnajat Ciamis.

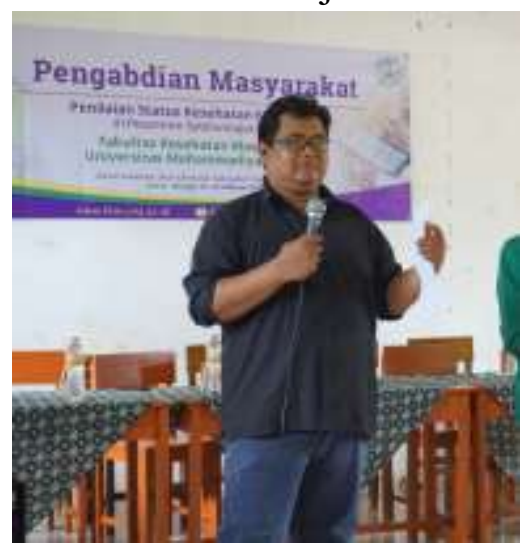

Sumber: Data primer 2020

Gambar 1. Kegiatan penyuluhan kesehatan pencegahan penyakit Tuberkulosis di Pesantren Sabilunnajat Ciamis

Pengendalian risiko untuk kasus tuberkulosis menurut peraturan menteri kesehatan bukan hanya penyuluhan kesehatan dalam hal ini promosi lingkungan dan hidup sehat, namun juga terdapat penemuan aktif berbasis keluarga dan masyarakat. Penemuan aktif berbasis keluarga dan masyarakat ini dapat dilakukan melalui kegiatan investigasi kontak pada santri yang pernah kontak dengan pasien Tuberkulosis atau ditanyakan tentang kemungkinan adanya orang yang tinggal serumah atau sekamar memiliki penyakit TB atau yang memiliki gejala Tuberkulosis. Maka penting adanya untuk berkomunikasi dengan pihak puskemas untuk skrinning aktif disetiap pesantren. Pesantren sendiri merupakan populasi berisiko terhadap kasus tuberkulosis karena memiliki karakteristik hunian yang padat dan interaksi yang sangat intens diantara santri.

Dalam studi lain yang dilakukan pada Santri Madrasah Aliyah Pesantren Khulafaur Rasyidin didapatkan informasi bahwa penyuluhan bisa meningkatkan pengetahuan terkait kasus TB Paru. Selain itu didapatkan informasi jika menggunakan media audio visual akan lebih signifikan (Muthia F, Fitriangga A, Yanti SN, 2016)

Selain melakukan penyuluhan kesehatan, dalam kegiatan pengabdian masyarakat ini juga dilakukan pengobatan gratis di pesantren Sabilunnajat.

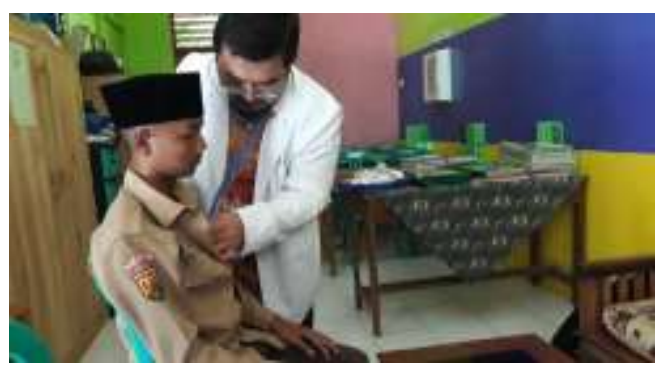

Sumber: Data Primer, 2020

Tabel 2. Kegiatan Pengobatan Gratis pada Santri di Pesantren Sabilunnajat. 
Sebagian besar penyakit yang ditemukan adalah penyakit kulit dan pernafasan. Disela-sela pengobatan dilakukan juga kegiatan privat edukasi pencegahan penyakit dan kebersihan diri pada santri.

\section{KESIMPULAN DAN SARAN}

Kegiatan pengabdian kepada masyarakat yang telah dilakukan menunjukkan bahwa terdapat perbedaan sebelum dan sesudah penyuluhan kesehatan pencegahan penyakit tuberculosis di pondok Pesantren Sabilunnajat. Saran yang diberikan kepada pihak sabilunnajat agar selalu menjaga kesehatan dan menerapkan perilaku hidup bersih dan sehat kepada para santri.

\section{UCAPAN TERIMA KASIH}

Kami mengucapkan terima kasih kepada seluruh pengurus Pondok Pesantren Sabilunnajat yang telah memberikan kami ruang untuk melakukan pengabdian masyarakat dalam bentuk penyuluhan kesehatan tuberculosis. Semoga bisa bermanfaat bagi umat umumnya dan pada santri khususnya.

\section{DAFTAR PUSTAKA}

Kemenkes RI. 2019. Profil Kesehatan Indonesia 2018. Jakarta.

Menteri Kesehatan. 2016. PERATURAN MENTERI KESEHATAN REPUBLIK INDONESIA NOMOR 67 TAHUN 2016 TENTANG PENANGGULANGAN TUBERKULOSIS. Menteri Kesehatan. Jakarta.

Muthia F, Fitriangga A, Yanti SN. 2016. Perbedaan Efektifitas Penyuluhan Kesehatan menggunakan Metode Ceramah dan Media Audiovisual (Film) terhadap Pengetahuan Santri Madrasah Aliyah Pesantren Khulafaur Rasyidin tentang TB Paru Tahun 2015. Jurnal Cerebellum. Volume 2. Nomor 4.

World Health Organization. 2018. Global Tuberculosis Report 2018.

World Health Organization (WHO). 2014. Global Tuberculosis Report, Geneva: WHO Library.

Setiarni SM, Sutomo AH, Hariyono W. 2011. Hubungan antara tingkat pengetahuan, status ekonomi dan kebiasan merokok dengan kejadian tuberculosis paru pada orang dewasa di wilayah kerja puskesmas Tuan Tuan Kabupaten Ketapang Kalimantan Barat.KES MAS Vol. 5, No. 3. hal: 162-232.

Wenas, AR, Kandou GD, Rombot DV. 2015. Hubungan perilaku dengan kejadian penyakit TB di Desa Wori Kecamatan Wori Kabupaten Minahasa Utara. Jurnal Kedokteran Komunitas dan Tropik : Volume III Nomor 2. 